\title{
Physiological Linguistics, and Some Implications Regarding Disciplinary Autonomy and Unification
}

\author{
SAMUEL D. EPSTEIN
}

\begin{abstract}
Chomsky's current Biolinguistic (Minimalist) methodology is shown to comport with what might be called 'established' aspects of biological method, thereby raising, in the biolinguistic domain, issues concerning biological autonomy from the physical sciences. At least current irreducibility of biology, including biolinguistics, stems in at least some cases from the very nature of what I will claim is physiological, or inter-organ/inter-component, macro-levels of explanation which play a new and central explanatory role in Chomsky's inter-componential (interface-based) explanation of certain (anatomical) properties of the syntactic component of Universal Grammar. Under this new mode of explanation, certain physiological functions of cognitive mental organs are hypothesized, in an attempt to explain aspects of their internal anatomy. Thus, the internal anatomy of the syntactic component exhibits features that enable it to effectively interface with (i.e. function in a coordinated fashion with) other 'adjacent' organs, such as the Conceptual-Intensional (C-I) ('meaning') system and the SensoryMotor (SM) ('sound') system. These two interface systems take as their inputs the assembled outputs of the syntactic component and, as a result of the very syntactic structure imposed by the syntax (as opposed to countless imaginable alternatives) are then able to assign their (linearized) sound and (compositional) meaning interpretations. If this is an accurate characterization, Chomsky's long-standing postulation of mental organs, and I will argue, the advancement of new hypotheses concerning physiological inter-organ functions, has attained in current biolinguistic Minimalist method a significant unification with foundational aspects of physiological explanation in other areas of biology.
\end{abstract}

\section{Introduction}

This paper has two main goals. One is simply to suggest that there are some striking and potentially quite important, but perhaps unrecognized, similarities between Chomsky, 2005 ('Three factors in language design') and central aspects of Mayr, 2004 (What Makes Biology Unique? Considerations on the Autonomy of a Scientific Discipline). The potential importance of these similarities is at least

\footnotetext{
I thank, in addition to the Mind $\&$ Language reviewers, Dr. Guy Longworth of Mind \& Language for his kind and professional assistance throughout the review process. I am also indebted to the following people for extremely helpful discussion and comments on earlier drafts: Catherine Fortin, Randy Gallistel, Sam Gutmann, Rick Lewis, Guy Longworth, Jim McGilvray, and Marilyn Shatz. I owe a very special thanks to Noam Chomsky, Josh Epstein, Daniel Seely and Neil Smith for extensive discussion and help. None of the aforementioned necessarily agree with anything written here.
}

Address for correspondence: Department of Linguistics, University of Michigan, 1175 Undergraduate Science Building, 204 Washtenaw Avenue, Ann Arbor, MI 48109-2215, USA.

Email: sepstein@umich.edu 
two-fold; first, it illustrates to practicing linguists, especially to a linguist such as myself - who is by no means a biologist-how directly Chomsky's current Biolinguistic Minimalist methodology comports with what might be called 'established' aspects of biological method—at least as conceived by Mayr. Second, I will suggest that some of the possible challenges, or skepticism, facing contemporary biolinguistic method may mimic similar, and in some cases precedented, challenges or skepticism which faced the emerging field of biology, which as Mayr's title suggests, struggled (and arguably still struggles) to maintain autonomy from other scientific disciplines.

The 'autonomy' question directly relates to issues concerning scientific theory reduction, in particular the possibility of reducing biology to physics. I suggest that at least current irreducibility in biology, including biolinguistics, stems in at least some cases from the very nature of what I will claim is physiological, or inter-organ/inter-component, levels of explanation. These play a central role in Chomsky's inter-componential (interface-based) explanation of properties of the syntactic component of Universal Grammar. Specifically at issue is Chomsky's recent attempt to explain certain hitherto stipulated constraints on syntactic mechanisms in terms of the syntactic component having to assemble (or generate) outputs that satisfy distinct interpretive components of sound and meaning, the so-called Output Conditions. Thus the properties of one component of a system (the syntax) are in part to be explained by its outputs having to meet the demands imposed by other components, external to it, but with which it interfaces. The components that take in the products of the syntax are the two interpretive components: one assigns a phonological interpretation, the other a semantic interpretation to structured representations assembled by the syntax. Can the formal properties of the syntactic subsystem of Universal Grammar be (in part) explained by this syntactic subsystem having to meet the dual (and disparate) demands of phonological and semantic interpretability? Under this mode of explanation-seeking inquiry, certain physiological functions of mental organs are being hypothesized, along with equally empirical hypotheses regarding the (anatomical) structure of these organs. Thus, I take seriously the hypothesis that the language faculty is 'organ-ized', i.e. an organ of the body (Chomsky, (as early as) 1975 and (as recently as) 2005), along with other cognitive systems. With Gallistel (2005), I assume that the problem of explaining human language acquisition, the growth of linguistic knowledge in the individual:

$\ldots$ is so formidable that there is no hope of surmounting it without a taskspecific learning organ... with a structure tailored to the demands of this particular domain (Gallistel, 2005, p. 2).

(I also agree with Gallistel that the vague notion of 'General Purpose Learning' is scientifically wholly inadequate and unable to account for any other specialized cognitive feats performed by other organisms, e.g. the dead-reckoning 
[path-integration] algorithm used in insect navigation.) ${ }^{1}$ As concerns the human language organ, I also follow Gallistel in adopting the following perspective:

Whether this organ is a highly localized part of the brain or arises from a language specific interconnection of diverse data-processing modules in the brain is irrelevant to whether it constitutes a distinct organ or not. Some organs are localized (for example the kidney) while others ramify everywhere (for example the circulatory system) (Gallistel, 2005, p. 2).

As concerns such organs, and their physiological function, Gallistel adopts the following (I believe partly physiological, partly anatomical) characterization of an organ:

The essential feature of an organ is that it has a function distinct from the function of other organs and a structure suited to that function, a structure that makes it possible for it to do its job (Gallistel, 2005, p. 2).

If the arguments I provide below are on track, Chomsky's long-standing postulation of mental organs, and I will argue, the advancement of new hypotheses concerning physiological inter-organ functions, has effected in current biolinguistic Minimalist method a significant unification with foundational aspects of anatomical, coupled with physiological, modes of inquiry and explanation in other areas of biology. (For an excellent and accessible discussion of Chomsky's notion of a language organ, but not inter-organ function, my focus here, see Anderson and Lightfoot, 2002.) Ignorance of the history of (I think highly questionable) opposition to such forms of inquiry and explanation in (non-cognitive) biological domains increases the odds of unwittingly repeating this same history in the biolinguistic arena, and perhaps this repetition has already begun. For some recent discussion, see e.g. Jenkins, 2000 and Boeckx, forthcoming. With hope, this paper clarifies to at least some degree, the nature, progress and promise of this new mode of physiological, inter-organic linguistic inquiry and explanation as pioneered in Chomsky's recent unifying Minimalist research method, within which, I argue, not only the internal anatomy of individual organs is explored (e.g. the anatomy/structure of universal mechanisms of human syntactic subsystems), but inter-organic physiological function is also postulated. The anatomy or structure of the syntactic component is such that this organ can effectively interface with (i.e. function in a coordinated fashion with) other organs, such as the ConceptualIntensional (C-I) ('meaning') system and the Sensory- Motor (SM) ('sound')

See, among many other works by Gallistel, 2006. For an excellent and engaging non-technical overview of the myriad cognitive-mathematical abilities of various organisms (from dogs to lobsters to ants) see Devlin, 2005. 
system, the interface systems that take as their inputs the outputs of the syntactic component and impose upon these syntactically structured representations sound and meaning interpretations.

\section{Chomsky's Three Factors and Mayr's Principle of Dual (actually, Triple) Causation}

Arguably, the central point made in Chomsky, 2005 is to revisit an important insight already broached, albeit briefly, in at least Chomsky (1988, pp. 167, 189) and Chomsky (1965, p. 59) regarding the roles of biology and of physics in determining properties of the human language faculty. Chomsky advances the following partly methodological hypothesis, which comports with the Minimalist (more generally, scientific) method of trying to explain (not merely describe) aspects of the natural world - in this case, individual human knowledge of language, a property of individual organisms, hence a bio-physical entity.

Assuming that the faculty of language has the general properties of other biological systems, we should, therefore, be seeking three factors that enter into the growth of language in the individual:

1. Genetic endowment ... which determines the general course of the development of the language faculty. ...

2. Experience, which leads to variation, within a fairly narrow range, as in the case of other subsystems of the human capacity and the organism generally.

3. Principles not specific to the faculty of language.

The third factor falls into several subtypes: (a) principles of data analysis that might be used in language acquisition and other domains; (b) principles of structural architecture and developmental constraints that enter into canalization, organic form, and action over a wide range, including principles of efficient computation, which would be expected to be of particular significance for computational systems such as language. It is the second of these subcategories that should be of particular significance in determining the nature of attainable languages (Chomsky, 2005, p. 6).

I believe that Chomsky's three-factor perspective and Mayr's 2004 principle of dual (in fact, triple) causation in biology are very closely related. Importantly, Mayr identifies this multiple causation as a defining characteristic of biology that is directly responsible for its disciplinary autonomy, specifically, its irreducibility to physics. Mayr writes:

... all biological processes differ in one respect fundamentally from all processes in the inanimate world; they are subject to dual causation. 
In contrast to purely physical processes, these biological ones are controlled not only by natural laws but also by genetic programs. This duality fully provides a clear demarcation between inanimate and living processes (Mayr, 2004, p. 30).

Thus, Mayr crucially assumes that what makes biology unique (and, as will be discussed below, irreducible to physics in Mayr's view), is dual causation, i.e. the role of both (1a) and (1b).

\section{(1) a. Genetic Programs \\ b. 'Natural Laws'}

The kind of genetic program operative in the human language faculty (as it is conceived by Chomsky) is an 'open program' (not a 'closed program') in Mayr's sense of this term:

... open programs $[. .$.$] are constituted in such a way that additional information$ can be incorporated during a lifetime ... In the famous case of the following reaction in the young gosling, the open program provides for the 'following reaction', but the particular object ('the parent') to be followed is added by experience (by 'imprinting') (Mayr, 2004, p. 54).

Thus, for both Chomsky and Mayr, there are in fact three factors that must be distinguished, and identified correctly, in determining the nature of the various properties of organisms.

(2) The Three Factors

a. Genetics, in particular open programs (for Chomsky, fixed Principles and open Parameters of Universal Grammar);

b. The limited effect of the environment/experience such that 'additional information' (Mayr) can be incorporated (= parameter setting, or re-setting, under exposure to, and analysis of, environmental linguistic input to the developing child, e.g. exposure to Swahili vs. German input for Chomsky);

c. Natural laws (Mayr), factors independent of the genetically determined aspects of the open program (= Chomsky's third factor, e.g. 'principles of structural architecture and developmental constraints ... that enter into organic form ...').

It is merely a terminological idiosyncrasy that Mayr collapses (2a) and (2b) into the seemingly single notion 'open program'; i.e. the program is largely fixed by genetics (a human embryo cannot develop into a horse), but aspects are sufficiently plastic to be influenced by environmental input, e.g. whether a baby will develop 
knowledge of Japanese or of German. Open programs and natural law constitute Mayr's 'dual causation'.2

In sum, I think that Chomsky's current Minimalist biolinguistics embraces the same foundational, if not defining, methodology expressed by Mayr's philosophy of (what he regards as) the autonomous field of biology. If that's an accurate characterization, Chomsky has effected in his current framework of Three Factor Biolinguistic Minimalism a significant unification with foundational aspects of biological inquiry which presume that organic structure and growth is determined by three factors. The remainder of this paper explores some aspects of this three factor approach to the nature and growth of the human language organ, while also discussing what I believe to be Chomsky's path-breaking exploration of the physiological function (as opposed to 'mere' internal anatomy) of the language organ within the larger system of organs within which it operates. ${ }^{3}$

\subsection{Teleonomic versus Teleomatic Processes}

Given his principle of dual causation, Mayr dedicates a significant amount of discussion to the corresponding distinction between what he calls 'teleomatic' versus 'teleonomic' processes. This duality is offered as an alternative to 'cosmic teleology', the belief that 'there is a trend in the world toward progress or perfection' held by 'the most determined opponents of natural selection ... .(Mayr, 2004, p. 59-60).

For Mayr, teleomatic processes:

... come to an end when the potential is used up (as in the cooling of a heated piece of iron) or when the process is stopped by encountering an external impediment (as when a falling object hits the ground). The law of gravity and the second law of thermodynamics are among the natural laws that most frequently govern teleomatic processes (Mayr, 2004, p. 50).

As concerns this distinction between teleomatic and teleonomic processes, Mayr writes:

the very general terminal situations effected by natural laws are something entirely different from the highly specific goals coded in programs.

2 Newell (1990, p. 42) seems to propose a similar three-factor framework in investigating human cognition more generally:

Theories of human cognition are ultimately theories of physical biological systems. Our ability to describe human cognition in one way rather than another rests ultimately on the physical and biological nature of human beings. Furthermore the fact that human beings are grounded in the world implies additional constraints that must be taken into account in constructing our theories.

3 One possible, but not clear, dissimilarity between Chomsky and Mayr in this regard may lie in the former using the term 'factor' and the latter 'cause(ation)'. I will not analyze this issue here. 
The existence of programs, of course, is in no way in conflict with natural laws. All the physiochemical processes that take place during the translation and execution of a program strictly obey natural laws.

By contrast with teleomatic processes, teleonomic processes are goal-directed and the goal directness of such processes is due (not to cosmic teleology, but) to the operation of an evolved program:

The existence of teleonomic processes regulated by evolved programs is the reason for the dual causation in biology, due to the natural laws (as in the physical sciences) and due to genetic programs (not found in the physical sciences).... It is important ...to emphasize...that the goal of a teleonomic activity does not lie in the future but is coded in the program. Not enough is known about the genetic molecular basis of such programs to permit us to say much more than that they are innate or partly innate. The existence of the program is inferred from its manifestations in the behavior of the activities of the bearer of the program (Mayr, 2004, p. 53-4).

The similarity to Chomsky's three-factor approach should be clear. Importantly, the as yet undiscovered genetic-molecular bases of such programs is, according to Mayr, pervasive in the biological sciences, yet many scholars nonetheless incorrectly claim that it reflects an 'immaturity' of biological science (see Mayr, 2004, p. 79). 'Ignorance' of the genetic molecular basis of such programs is therefore not an idiosyncratic 'shortcoming' peculiar to current biolinguistics, nor an 'unreal abstractness' in linguistics or cognitive psychology, more generally. (For a recent discussion of persisting deep-seated confusions regarding 'reality versus abstractness' in linguistics, and in science more generally, see Epstein and Hornstein, 2005). Generalizing even further, as Chomsky (p.c.) points out, the same situation characterizes scientific development in other areas, e.g. many significant achievements of astronomy having been attained long before the molecular basis of the planets was known or even imagined.

In the next section, I discuss 'levels of explanation' and suggest that a failure to recognize the different levels of analysis at which illumination may occur may underlie such charges of insufficiency of all but genetic-molecular, or alternatively physical, explanation. Regardless, it is important that 'charges' of current irreducibility not be leveled against biolinguistics alone, if in fact these alleged criticisms are applicable to aspects of contemporary biological science in general, the autonomy (i.e. irreducibility) of which, recall, is Mayr's (2004) central dual causation thesis. The same goes for the apparently biological (not linguistically unique) method, pioneered in the 1950s by Chomsky in the linguistic domain, by which (to repeat):

the existence of the innate or partly innate program, about which we have insufficient genetic-molecular knowledge, is inferred from its manifestations 
in the behavior of the activities of the bearer of the program (Mayr, 2004, pp. 53-4).

\section{Reduction, Levels of Analysis and Explanation}

Mayr's stance regarding reduction of the biological sciences to the physical sciences may also resemble Chomsky's position regarding the corresponding question of biolinguistic reducibility to physical science. It seems to me that, in Mayr's view, to obey or conform to natural laws (as Mayr assumes all biological processes do) is not to be illuminated or explained by them. Mayr illustrates:

... to neglect the role of information and instruction inevitably results in a most misleading description of a program. Could one explain [my emphasis] a computer strictly in terms of natural laws, carefully avoiding any reference to information and instruction?

Similarly, Newell (1990, p. 47) writes,

A computer system can be described in many ways. It can be described as a system of electronic devices, or as an electrical circuit, or as a logic circuit, or as a register transfer system, or as a programming system. There are other ways as well, ways that are not related to its primary function, such as an item of cost in a budget, a contributor to floor loading, or an emblem of being high-tech.

In a similar vein, Lange (2004, p. 108) (opposing Rosenberg's 2001 reductionist position; see also Mayr, 2004, p. 80) discusses the autonomy of functional biological explanation as follows:

Take the explanation that the vulture has no feathers on its head and neck because the vulture feeds by sticking its head and neck deep inside the bodies of carrion, so any feathers there would become matted and dirty. This explanation is independent of the details of the laws of physics. Putnam uses a similar example to defend the irreducibility of macro-explanations; why a cubical peg, 15/16' on a side, cannot fit into a round hole 1 ' in diameter.

Putnam writes:

The explanation is that the board is rigid, the peg is rigid, and as a matter of geometric fact, the round hole is smaller than the peg... That is a correct explanation whether the peg consists of molecules, or continuous rigid substance, or whatever (1975, p. 296). 
Lange continues (2004, p. 109):

A peg (or vulture) made of continuous rigid substance would violate laws of physics. But the same functional explanation would apply to it. That distinctive range of invariance reflects the irreducibility of this kind of explanation to anything that could be supplied, even in principle, by the laws of physics ...

Here, the notion 'level of analysis' seems crucial. Putnam and Lange's points are that explanation of the unfitting peg/featherless vulture neck lies at a macro/functional level, not at the molecular, or for that matter, any physical level, in the opinions of Putnam and Lange. Similarly, Cummins (2002, p. 4) characterizes a certain description of a mechanical gate-opening Rube Goldberg device as follows:

... the components are identified functionally and their interactions are described in a way that necessarily abstracts away from the medium-dependent details.

In what I hope is accurately characterizable as a (fitting) analog to Putnam's unfitting peg argument, Mayr writes:

Nothing is as characteristic of biological processes as interactions at all levels ... the interaction of the components [my emphasis] must be considered as much as the properties of the isolated components (Mayr, 2004, p. 34-5).

In precisely the same vein, the renowned evolutionary biologist and geneticist Dobzhansky (1969, p. 170) writes that:

A biologist is faced with several hierarchically superimposed levels of integration of structures and functions.

And:

Organic phenomena are, indeed, patterns of chemical and physical components. There is no vital force, no entelechy, no psyche. The point is, however, that understanding the patterns is just as essential and exciting as understanding the components. A mosaic picture consists of stones of various colors, but it is a pattern, not a pile of stones. A living body is not a mixture of chemicals stirred together; it is an integrated system which arose gradually during the two billion years of organic evolution (Dobzhansky, 1969, p. 171).

The view is shared by his colleague, the microbiologist Dubos (1965):

In the most common and probably the most important phenomena of life, the constituent parts are so interdependent that they lose their character, their 
meaning, and indeed their very existence, when dissected from the functioning whole (as cited by Dobzhansky, 1969, p. 166).

Chomsky (p.c.), I think, shares this view by distinguishing what he calls metaphysical reductionism and epistemological anti-reductionism. Chomsky writes:

Metaphysical reductionism holds that we can explain genetic and computer programs, etc., in 'physical' terms - which simply amounts to saying that there is a naturalistic explanation, since the notion 'physical' is open-ended. Epistemological anti-reductionism holds that to capture what is actually happening in the world, many differing scales are appropriate: for determining the earth's orbit around the sun we don't have to pay attention to whether Jones put a dish on the table, or whether the table is round or square. In fact, we can treat earth as a mass point. Same with any kind of problem. There's no conflict between metaphysical reductionism and epistemological antireductionism.

This same issue concerning reduction in the linguistic domain is addressed by Smith (2002, p. 68):

... it doesn't follow that that physiological generalizations can be stated... in the vocabulary of particle physics any more than it follows that... linguistic generalizations can be stated in the vocabulary of neuroanatomy.

Poeppel and Embick's (2004) discussion of unification between linguistics and neuroscience is also relevant here. They identify two problems, characterized in (3) and (4) below.

(3) The Granularity Mismatch Problem:

'Linguistic and neuroscientific studies of language operate with objects of different granularity. In particular, linguistic computation involves a number of finer-grained distinctions and explicit computational operations. Neuroscientific approaches to language operate in terms of broader conceptual distinctions.'

(4) The Ontological Incommensurability Problem:

'The fundamental elements of linguistic theory [e.g. syllable, clause] cannot be reduced or matched up with the fundamental biological units identified by neuroscience [e.g. neuron, cortical column].'

As Poeppel and Embick (p. 6) note, it is unreasonable to require that all linguistic entities must have visible reflexes in current imaging (or lesion or psycholinguistic) data; with (p. 13) the basic assumption being that we study aspects of brain function by relying on, and thus being guided by, 'a system whose functional architecture 
is well understood'. The solution to these problems rests in their view on the notion we've been discussing, namely 'levels of abstraction' or scale.

We suggest a straightforward solution... namely spelling out the ontologies and processes in computational terms that are at the appropriate level of abstraction [my emphasis] (i.e. can be performed by specific neuronal populations) such that explicit interdisciplinary linking hypotheses can be formulated (Poeppel and Embick, 2004, p. 5). ${ }^{4}$

As Gallistel (2006, p. 70) elegantly notes, 'If behavior is the last court of appeal, then there are mechanisms in the nervous system not yet dreamed of in the philosophy of neuroscientists'. And, moreover, this kind of cross-disciplinary incommensurability is by no means unprecedented. As Gallistel further notes (2006 and p.c.), the classical geneticists' 'abstract' concept of a gene was biochemically unintelligible, hence seemed senseless to biochemists of the time. Yet the abstract concept in fact guided the very search that led to the molecular discoveries, and, importantly, these discoveries did not wholly replace or subsume the classical genetic level of analysis, which remains.

This same perspective regarding levels of analysis and their role in explanation, regardless of the domain of inquiry, is generally expressed by Whitehead (1938) when he suggests that:

... understanding always involves the notion of composition. This notion can enter in one of two ways. If the thing understood be composite, the understanding of it can be in reference to its factors, and to their ways of interweaving so as to form that total thing. This mode of comprehension makes evident why the thing is what it is. The second mode of understanding is to treat the thing as a unity, whether or not it is capable of analysis, and to obtain evidence as to its capacity for affecting its environment. The first mode may be called the internal understanding, and the second mode is the external understanding.... The two modes are reciprocal; either presupposes the other. The first mode conceives the thing as an outcome, the second mode conceives it as a causal factor... (Whitehead, 1938, p. 45-6).

The fact that each of Whitehead's two modes of understanding presupposes the other is not a contradiction or an indication of circularity, but an unavoidable

4 On the important difference between the reduction of one science wholly to another versus unification-via-disciplinary revision, see Chomsky (e.g. 2002, pp. 54-6). For incisive discussion of the disunity of the sciences, including specific discussion of psychology and its relation to neurology and neurology's relation to physics, see Fodor, 1974. As Fodor notes, 'Reducibility to physics is taken to be a constraint upon the acceptability of theories in the special sciences, with the curious consequence that the more the special sciences succeed, the more they ought to disappear'. 
feature of trying to rationally determine the properties of interacting systems. The same perspective is expressed by Chomsky when he writes of the relation between the syntax and the sound-meaning interfaces whose assembly requirements are by hypothesis met by efficient (arguably, third factor) application of the operations applied within the syntax.

We can regard an explanation of properties of language as principled insofar as it can be reduced to properties of the interface systems and general considerations of computational efficiency and the like. Needless to say, these 'external' conditions are only partially understood, we have to learn about the conditions that set the problem in the course of trying to solve it. The research task is interactive ... not an unfamiliar feature of rational inquiry (Chomsky 2005, p. 10).

\section{Chomsky's Physio-Syntactic Analysis: 'External' Explanation at the Component-Interaction Level}

The explanatory power of the macro level of analysis and its irreducibility is emphasized by Mayr:

What counts in the study of a complex system is its organization. Descending to a lower level of analysis often decreases the explanatory power of the preceding analysis ... (Mayr, 2004, p. 72).

And so,

Reduction, by failing to consider the interaction of components, fails to fulfill what it promises ... (Mayr, 2004, p. 80).

Echoing Putnam's cubical peg/round hole argument, Mayr notes that the explanatory value of functional explanation extends to inanimate objects as well, noting that the internal (in Whitehead's sense) composition of a hammer's handle, e.g. wood versus steel, is irrelevant to an explanation of its function. That is, it is the (inter-componential) combination/organization of the handle as joined with hammerhead that permits the explanation of its function. 'A further downward analysis adds nothing, ${ }^{5}$

Importantly, Chomsky (2005, and earlier) addresses this very issue of levels of explanation, in his discussion of Gallistel's (1997) compelling evidence that learning is based on specialized mechanisms, or 'organs within the brain', writing:

The modular view of learning of course does not entail that the component elements of the module are unique to it; at some level, everyone assumes that

5 As Neil Smith (p.c.) notes, this is reminiscent of Fodor's 1974 attack on reductionism regarding the likely irreducibility of Gresham's Law to physical principles. 
they are not - the cellular level for example - and the question of the level of organization at which unique properties emerge remains a basic one ... (Chomsky, 2005, p. 5).

Chomsky's point is clear. Levels of analysis and macro-level emergence play a vital role in (biological), hence biolinguistic, explanation.

I propose that the levels of analysis of the human language faculty, although not labeled as such, include, within the recent Minimalist Program, (5) and (6) below.

(5) Within-organ anatomical analysis, e.g. analysis of the structure of the syntactic component (as a recursive assembler) displaying the property of discrete infinity.

(6) Inter-organ (physiological function) analysis, whereby the or a function of the syntax is to produce outputs (assemblages) that satisfy the bare output conditions imposed by 'adjacent organs' that interface with the narrow syntax, namely the interface systems C-I and SM, which demand that syntactic assemblages be 'semantically' and 'phonologically' interpretable.

As a somewhat simplified, partly anachronistic, but concrete, illustration of this mode of explanation-whereby the syntax is party explained by its appeal to (inter-organ) physiological function of having to meet the demands imposed by the sound and meaning interpretive components external to it-consider the case of standard (syntactic) theory phrase structure rules such as (7).

\section{(7) Noun Phrase $\rightarrow$ determiner noun.}

Such a rule characterizes (your) knowledge that a noun phrase (in English) can consist of any determiner immediately followed by any noun. Such rules were initially stipulated, hence unexplained, aspects of human linguistic cognition. The question 'Why do all syntactic systems of (by hypothesis) all human languages contain phrase structure rules?' was unanswered (if ever asked).

A defining formal characteristic of such rules is that each one expresses two kinds of information, namely containment relations and precedence relations. For example, (7) above expresses your knowledge that

(8) a. A noun phrase may consist of, or contain, two elements, namely a determiner and a noun. Equivalently, a set of the form noun, determiner $\}$ is known by you to be one kind of noun phrase.

b. The determiner (e.g. the) precedes the noun (e.g. dog).

Containment information, as in (8a), is arguably universal; by hypothesis, it is not an idiosyncrasy of English that noun phrases can contain a determiner and a noun 
(and we expect no human language to, e.g., have noun phrases containing just a verb and a preposition). Precedence information, as in (8b), is by hypothesis language particular, and so we are unsurprised to find word-order variation among human languages.

'Why do human syntactic systems include such phrase structure rules, specifying containment and precedence?' An answer, appealing to physiological function, runs as follows: 'It is no accident or mystery that syntactic phrase structure rules specify precisely containment and precedence relations.' The semantics requires set representation, i.e. containment relations, so that it 'knows' what is to be semantically composed with what. Thus, the syntax provides the semantics with unambiguous unique assemblages. Thus, e.g. the set representation/ assemblage in (9),

(9) [old men] and [women],

receives a compositional semantic interpretation different from the semantic interpretation assigned to the syntactic representation in (10),

(10) old [men and women].

However, the phonology or articulatory system cannot successfully implement or execute these semantically necessary containment/set representations, since, unlike semantic composition, articulation involves phono-temporal ordering (you can't say the dog 'all-at-once'). Thus, it is no accident that the syntax also supplies ordering, or precedence, relations. In sum, the syntax specifies containment since this type of information is required for compositional semantic interpretation, and the syntax also specifies order since articulatory implementation requires it. Thus, the fact that phrase structure rules (the very backbone of the standard theory of syntax) specify such information needs no longer by considered axiomatic, but rather becomes physiologically explicable, in terms of the syntax producing representations that satisfy the demands imposed by adjacent organs, namely the interpretive components of sound and meaning, which take syntactic outputs as their inputs. As we'll discuss momentarily, the bio-minimalist perspective is completed under the hypothesis that phrase structure rules provide precisely such information-no less and no other superfluous information-and thus constitute not only a 'solution' to the demands imposed by the interfaces, but an optimal one. ${ }^{6}$

6 For more contemporary and formal discussion of syntactic containment and precedence as an 'optimal solution' within a current derivation-based Minimalist system incorporating Bare Phrase Structure (Chomsky, 1994) and the Linear Correspondence Axiom (Kayne, 1994), see Epstein et al, 1998, Section 6.4. 


\section{Chomsky's Physiological-Syntax, Component Interaction and Hempel's Logic of Functional Explanation}

\subsection{Introduction}

Before proceeding it is important to avoid a possible terminological confusion. Throughout this paper, I use the term 'physiological' or 'physiological function' in the following sense: characteristic of the normal inter-componential functioning of an organism. Crucially, 'function' in this context is NOT to be construed in the sense of 'functional' (e.g. strong adaptationist 'communicationbased') attempts to explain the presence or etiology of the design features of the language faculty. Rather my claim here is that Chomsky's inter-componential mode of explanation is standard physiology, addressing the circumscribed question 'How does it function within a larger system of which it is a part?' distinct from the evolutionary questions 'How did language arise?' and 'Does it confer a selectional advantage upon its bearers?', the latter being the standard, functionalist question 'What is language for?'. With Fitch Hauser and Chomsky, 2005, I regard such questions about 'language' as an unanalyzed whole, unproductive; and, as FHC note, even if circumscribed it may have the same unproductive quality as a question such as 'What is the brain for?' By contrast, standard physiology hypothesizes that one component of a biological system can be understood as functioning so as to produce outputs whose properties meet (or can meet, or to a certain degree meet) requirements imposed by a neighboring component that takes in these very outputs as its inputs. Following Cummins (1975, as cited by Grene and Depew, 2004, p. 316):

To ascribe a function to something is to ascribe a capacity to it which is singled out by its role in an analysis of some capacity of a containing system.

As concerns the historical role and productivity of such physiological analysis, and its current promise, Mayr relates the following:

When Harvey was asked what had induced him to think of the circulation of the blood, he answered 'I wondered why there were valves in the veins' (Krafft, 1982). Evidently they permit only a one-directional flow of the blood and this, almost automatically, led to an assumption of circulation. One physiological discovery after another resulted from asking 'Why?' questions concerning organs with unknown function ... and the heuristic value of this methodology has by no means been exhausted (Mayr, 2004, p. 59).

Similarly, Gallistel (2005, p. 1) writes:

Harvey (1628) revolutionized physiological thinking when he showed that the heart circulates the blood and that its structure suits it to perform this 
function ... . Chomsky (1975) reconceptualized learning in his Reflections on Language. His reconceptualization is as radical in its implications for psychology and neuroscience as Harvey's work was for physiology.

One of my central tenets in this paper is that Gallistel's likening of Chomsky (1975) to Harvey (1628) can and should be applied to the formal content of current Minimalist theory. Specifically, I think that Chomsky's new appeal to inter-organic linguistic explanation, in particular the central idea of the syntax formally operating in such a way as to satisfy the demands of the C-I (meaning) and SM (sound) interfaces (thereby seeking to explain previously stipulated syntactic mechanisms and constraints), is indeed physiological. (As concerns the importance of asking 'why' questions, e.g. 'Why does the syntax operate as it does?' and the unfortunate disparagement of such scientifically standard explanation-seeking in linguistics, see e.g. the introductions to Epstein and Seely (2002, 2006). Again, the comparison with biological inquiry is, I think, important.) Chomsky's question 'Why does the syntax operate as it does?' is qualitatively similar to Harvey's. Chomsky's answer in terms of inter-component function seems comparably physiological. Recall that, arguably, the leading idea of the Minimalist Program is the following:

If language is to be usable at all, its design must satisfy an interface condition IC; the information in the expressions generated by L, must be accessible to other systems including the SM (sensorimotor) and CI systems... Insofar as properties of $\mathrm{L}$ can be accounted for in terms of IC and general properties of computational efficiency...they have a principled explanation (Chomsky, 2001, p. 2).

Similarly,

... to what extent is the human faculty of language FL an optimal solution to minimal design specifications, conditions that language must satisfy to be useable at all? We may think of these specifications as legibility conditions for each language L (a state of FL), the expressions generated by L must be legible to systems that access these objects at the interface between FL and external systems-external to FL, internal to the person.

The strongest Minimalist thesis SMT would hold that language is an optimal solution to such conditions (Chomsky, 2001, p. 1).

And, similarly,

The components of expressions - their features, in standard terminologymust be interpretable by the systems that access them; the representations at the interface with sensorimotor and thought systems consist of interpretable features (Chomsky et al., 2002, p. 88). 
This is a, or perhaps the, central premise of Chomsky's inter-organ, physiosyntactic explanation, as examined in Epstein (2005). It appears centrally again in Chomsky's most recent work (2005, pp. 9-10):

We can...try to sharpen the question of what constitutes a principled explanation for properties of language, and turn to one of the most fundamental questions of the biology of language; to what extent does language approximate an optimal solution to conditions that it must satisfy to be usable at all, given extralinguistic structural architecture?...the expressions generated by a language must satisfy two interface conditions; those imposed by the sensorimotor system SM and by the conceptual-intentional system C-I ... .

I believe that this form of argument, or this empirical method closely corresponds to what Hempel (1959) discusses in his foundational paper, 'The logic of functional analysis', to which I turn in the next section.

\subsection{Hempel's Functional Analysis}

Again, it is important to note that 'functional' as used by Hempel has a very different meaning from 'functional' as it is used in the context of 'functional linguistics', the latter addressing questions such as 'What is language for?' (Again, following Fitch, Hauser and Chomsky, 2005, I believe that such questions are so vague as to be unproductive, for at least two reasons. First, the notion 'language' is presumed to be sufficiently clear (and indecomposable analytically) to advantageously pose the question presupposing the notion; but, arguably, it is not. Second, even if it were clear, or more clear, as might be e.g. the notion 'the brain', the question 'What is the brain for?' is arguably insufficiently clear to be productively addressed, just as Fitch, Hauser and Chomsky, 2005 note.) Hempel, rather, concerns himself with the following:

The kind of phenomenon that a functional ... analysis is invoked to explain is typically some recurrent activity or some behavior pattern in an individual or a group, such as a physiological mechanism [my emphasis] ... functional analysis seeks to understand [some phenomenon or property] ... . By determining the role it plays in keeping the given system in proper working order (Hempel, 1959, pp. 304-5).

As an example, Hempel considers the statement in (11).

(11) The heartbeat in vertebrates has the function of circulating blood.

Notice here the inter-componential nature of the statement: that is, the heartbeat constitutes a mechanism - a property of organ/component \#1 (it beats/contracts) that permits an interface with organ/component \#2 (e.g. the vascular/arterial 
systems). By analogy, consider the following passage from Chomsky, 2005 [with my inserts bracketed and italicized]:

We can...try to sharpen the question of what constitutes a principled explanation for properties of language [the cardiac system], and turn to one of the most fundamental questions of the biology of language [cardiological inquiry]; to what extent does language [the heart] approximate an optimal solution to conditions that it must satisfy to be usable at all, given extra-linguistic [extracardiological] structural architecture? ... the expressions generated by a language [cardiac output] must satisfy two interface conditions: those imposed by the sensori-motor system SM and by the conceptual-intentional system C-I [e.g. those imposed by the arterial and vascular systems with which the heart directly interfaces] ... (Chomsky, 2005, pp. 9-10).

Notice also that (11) is stated at a certain (higher) level of analysis at which we are unconcerned with e.g. the cellular composition of the heart (Whitehead's internal understanding); but we are regarding 'the heart' as a component of a system (Whitehead's external understanding), each component of which is, by hypothesis, characterized at 'the same level' of description. As Chomsky repeatedly notes, 'the human heart' (as e.g. depicted on a physician's wall poster) is an abstraction, lacking myriad properties of any existing 'real' heart, e.g. the differing decibel level produced by each beat.

As concerns this issue, Hempel raises the question, 'What is the difference between a function and an effect?' He points out that they are importantly different, as illustrated by the statements in (12) and (13).

(12) The heartbeat has the effect of producing heart sounds.

(13) The heartbeat has the function of producing heart sounds.

Hempel argues that the functional analyst would refuse to assert (13),

... on the grounds that heart sounds are an effect of the heartbeat which is of no importance to the functioning of the organism; whereas the circulation of the blood effects the transportation of nutriment to, and the removal of waste from, various parts of the organism-a process that is indispensable if the organism is to remain in proper working order, and indeed if it is to stay alive.

At least two issues now require clarification regarding this passage. First, as concerns the 'life or death' issue, within the linguistic domain, we are, by hypothesis, NOT claiming that the narrow syntax is a necessity for my current survival, akin to my survival depending upon now having a heart. That is, (were it possible) removal (without any replacement) of my cardiac system would cause immediate death, whereas, in the relevant sense, I think removal of my narrow syntax and replacement 
of it with a modified narrow syntax that failed to meet any requirements of the interfaces, would NOT, by hypothesis, result in my death. This is, of course, an 'abstract argument', as I assume, with Chomsky, that my syntactic system cannot be surgically removed anymore than my (rule governed, see e.g. Hoffman, 1998) visual system, or cardiac system as abstractly conceived, can be surgically removed. (Here, I leave aside the contentious debate regarding natural selection of the language faculty; see Jenkins, 2000 for extremely important discussion including the systematic misinterpretation and misrepresentation of Chomsky's position regarding this issue. $)^{7}$

Second, as Hempel realizes, his central functional distinction between heart as blood-circulator versus heart as sound-maker appeals to, and requires clarification of, 'proper working order', 'functioning', and the like, of the organism. Again, the heartbeat arguably plays a role in 'proper working order', while heartsounds do not. The (un)clarity of these terms leads Hempel to a certain, central reservation regarding the explanatory depth of functional explanation, to which we will return below.

If I am correct that my narrow syntax is NOT required, whereas my heartbeat is, for my continued individual survival, how can I possibly maintain my conjecture that Chomsky's analysis - and its concomitant attempt to explain properties of the narrow syntax - is indeed functional in Hempel's sense? Especially, since, as concerns individual survival, the cases seem radically different.

What I would like to suggest is that this relates intimately to what is meant by Hempel by terms such as 'proper working order'. But how is proper working order to be quantified? I think the answer crucially concerns, at least in part, inter-componential compatibility within a given system-are the outputs of component \#1 useable by component \#2? The criterion 'Is $\mathrm{X}$ necessary for the survival of the individual organism?' is largely irrelevant to quantifying the overall inter-component compatibility of the/a system. A human will die in an oxygen-free environment, but the deceased (organism), in the sense at hand, still displays considerable inter-componential physiological design-compatibility - it just happens to be dead! Similarly, inanimate objects can display degrees of inter-componential compatibility. The key to relating the two modes of explanation (Chomsky's and Hempel's) is, I believe, the following:

(14) At the inter-componential level of explanation of a given system, function is to be gauged in terms of the output of one subcomponent

\footnotetext{
It is important to note that here I am making an empirical claim regarding (a) physiological function, regarded as one property, of the current syntax. How the anatomy and physiology of this system evolved is a separate question from what the system currently consists of. In fact, the question 'How did IT evolve?' is dependent on some characterization of the current structure and function of that which evolved. For extensive discussion of the very serious problems and confusions inherent in attempting to explain certain current organic structures and functions exclusively in terms of natural selection (contra Darwin, who identified natural selection as one, not the only, factor in evolution), see e.g. Jenkins, 2000; Fitch, Hauser and Chomsky, 2005; Cummins, 2002; Atran, 2005; and Gould, 1985 (the latter regarding incipient stages and exaptation).
} 
consisting of products that are-to one degree or another-useable by the 'neighboring component' which takes these outputs as its inputs.

Heartsounds are not a function of the heartbeat, precisely because there is no auditory-processing system directly linked to the heart. If there were an auditory processing component directly linked to the heart, then by hypothesis, one function of the heart would be to feed this system with auditorily analyzable inputs, regardless of whether this overall systemic organization has or lacks Rube Goldbergian properties. Thus, physiological or 'functional' analysis of the intercomponent compatibility within a system is, by definition, orthogonal to the question of how the overall system might be used, or operate, as itself a component in a super-system containing it. The standard non-generative functional (communicative) question 'What is language for, or used for?' does not arise in this domain of inquiry, any more than the questions 'What is the brain for?' or 'What will Bill use his brain for?' arise in the cognitive and/or neurosciences.

This inter-component compatibility lies at the core of Hempel's characterization of the nature of functional analysis.

(15) Basic Pattern of a Functional Analysis:

The object of the analysis is some object $i$ (e.g., the beating of the heart) occurring in a system $s$ (e.g., the body of a living vertebrate). The analysis aims to show that $s$ is in a state, or internal condition $c i$, and in an environment representing certain external conditions $c e$, such that under conditions $c i$ and $c e$ (to be referred to jointly as $c$ ), the trait $i$ has effects which satisfy some 'need' or 'functional requirement' of $s$, i.e., a condition $n$ which is necessary for the system's remaining in adequate or effective, or proper, working order.

This, I believe, characterizes the general form of inquiry and analysis that Chomsky proposes, and is, I believe, a natural extension from Chomsky's postulation of mental organs. That is, with a preliminary hypothesis in hand as to the internal nature of the syntax organ, one can proceed to ask (in the manner of Whitehead's 'external understanding') its role, or function, as a component within a larger system of interacting components, essentially the field of physiology — as contrasted with anatomy - in (nonmentalist) biology. Recall:

We can...try to sharpen the question of what constitutes a principled explanation for properties of language, and turn to one of the most fundamental questions of the biology of language; to what extent does language approximate an optimal solution to conditions that it must satisfy to be usable at all, given extralinguistic structural architecture? .... the expressions generated by a language must satisfy two interface conditions: those imposed by the sensorimotor system SM and by the conceptual-intentional system C-I ... (Chomsky, 2005, pp. 9-10). 
Thus, following Aristotle (as Chomsky notes), 'language' has 'sound' and also 'meaning', and the syntax relates them, thereby generating pairs of sound-meaning representations. But for Chomsky, the syntax, SM, and C-I are each organs of the body, and so, I suggest, a (heretofore absent) physiological level of inter-organic function is postulated as an explanatorily central aspect of Chomsky's contemporary bio-linguistic Minimalist theory.

\subsection{Challenges to Hempel?}

The purpose of this brief section is simply to discuss previously-voiced potential reservations concerning the explanatory nature of Hempelian functional analysis, and to suggest that it is perhaps the case that opposition to Chomsky's analysis (physio-mentalist analysis, if I am on track) may well repeat a similar history of reservation towards, or opposition to, such modes of analysis.

To begin with, although Hempel claimed that functional analysis (again, meant here in the sense just discussed) has a definitely empirical core, he claimed that it constitutes neither a deductive nor inductive mode of inquiry/explanation. The obstacle to functional deductive explanation, in Hempel's view, is the existence of functional equivalents. Consider the following example: given an entire specification of human anatomy and physiology, minus the heart, we can not deduce (or induce) the existence of the human heart, but only a (non-unit) set of functionally equivalent blood-circulators (including, for example, a Jarvik artificial heart) serving the same function. Presumably there exist an infinite number of 'solutions' to the goal-directed challenge of pumping blood. In this regard, it is important to note that Hempel, although cautious, himself regards such analysis as 'illuminating suggestive and fruitful in a number of contexts' and 'at least ideally, as a program of inquiry' (Hempel, 1959, p. 330). This, of course, is strikingly reminiscent of Chomsky's careful (but sometimes misunderstood) use of the term (Minimalist) 'Program', and his explicitly discussed avoidance of the term 'Minimalist Theory'.

Interestingly, Nagel (1961) argued against Hempel's position regarding functional explanation, and claimed instead that functional analysis can, in principle, be made to fit the deductive pattern. Salmon summarizes:

Nagel is not moved by other possible devices, such as Jarvik artificial hearts, inasmuch as they do not circulate blood in normal human beings. He is equally unmoved by fictitious possibilities that are not realized in nature (Salmon, 1989, p. 115).

Arguably, the crucial notion, 'realizable in nature', directly relates to the nature of biophysical explanation (Mayr's dual causation/Chomsky's Three Factors) with which we began. My suspicion is that further inquiry into just such realizability in nature promises to elevate Chomsky's pioneering explanation-seeking Minimalist Program of inquiry to an even more deeply explanatory theory of human linguistic 
knowledge, which is precisely Chomsky's intent: inter-organ, physiological, and third factor explanation. As Chomsky notes, regardless of one's specific theoretical linguistic orientation, the well-established biological questions seem unavoidable in the linguistic domain, if as seems undeniable, we, like other (earthly) organisms, are part of the biophysical universe.

To sum up this section, there exists a precedented debate regarding the explanatory properties of such analyses, and varying views regarding the efficacy of such analysis as applied in various domains. If I am on track that Chomsky's Minimalist Program, and the central concept of the syntax satisfying the demands imposed by the interfaces, is indeed a form of inter-organ physiological mentalism (functional in Hempel's sense), then cognizance of the previous debates, confusions and indeterminacies regarding the nature of such analyses might inform the current debate concerning the productivity of such programs of inquiry which seek to determine the 'external' properties of a sub-system. If I am on track here, one essential feature of Minimalist physiology involves determining the 'external properties' of a sub-system, and then explaining some of the properties of a module by appeal to systems external to it. This is a necessary component of all understanding in Whitehead's view, and a component that is explanatorily irreducible in the minds of many.

Department of Linguistics University of Michigan, Ann Arbor

\section{References}

Anderson, S. and Lightfoot, D. 2002: Linguistics as Cognitive Physiology. Cambridge: Cambridge University Press.

Atran, S. 2005: Adaptationism for human cognition: strong, spurious or weak? Mind $\mathcal{E}$ Language, 20.1, 39-67.

Boeckx, C. Forthcoming: Linguistic Minimalism: Origins, Concepts, Methods and Aims. Oxford: Oxford University Press.

Chomsky, N. 1965: Aspects of the Theory of Syntax. Cambridge, MA: MIT Press.

Chomsky, N. 1975: Reflections on Language. New York: Pantheon.

Chomsky, N. 1988: Language and Problems of Knowledge: the Managua Lectures. Cambridge, MA: MIT Press.

Chomsky, N. 1994: Bare Phrase Structure. Occasional Papers in Linguistics 5. Cambridge, MA: MIT Press.

Chomsky, N. 2001: Beyond explanatory adequacy. Manuscript, MIT. A revised version appears in: A. Belletti (ed.) 2004: Structures and Beyond: Current Issues in the Theory of Language. Oxford: Oxford University Press.

Chomsky, N., Belletti, A. and Rizzi, L. (eds) 2002: On Nature and Language. Cambridge: Cambridge University Press.

Chomsky, N. 2005: Three factors in language design. Linguistic Inquiry, 36.1, 1-22. 
Cummins, R. 1975: Functional analysis. Journal of Philosophy, 72, 741-760. Reprinted in C. Allen, M. Bekoff, and G.V. Lauder (eds), 1998: Nature's Purposes: Analyses of Design and Function in Biology. Cambridge, MA: MIT Press.

Cummins, R. 2002: Neo-teleology. In A. Ariew, R. Cummins and M. Perlman (eds), Functions: New Essays in the Philosophy of Psychology and Biology. Oxford: Oxford University Press.

Devlin, K. 2005: The Math Instinct: Why You're a Mathematical Genius (Along with Lobsters, Birds, Cats and Dogs). New York: Thunder's Mouth Press (an imprint of Avalon Publishing Group, Inc.)

Dobzhansky, T. 1969: On Cartesian and Darwinian aspects of biology. In S. Morgenbesser, P. Suppes and M. White (eds), Philosophy, Science and Method: Essays in Honor of Ernest Nagel. New York: St. Martin's Press.

Dubos, R. 1965: Man Adapting. New Haven, CT: Yale University Press. As cited by Dobzhansky, 1969.

Epstein, S. 2005: On I(nternalist)-Functional explanation in Minimalism. To appear in K. Grohmann (ed.), A special edition of Linguistic Analysis, 'Dynamic Interfaces'.

Epstein, S., Groat, E., Kawashima, R. and Kitahara, H. 1998: A Derivational Approach to Syntactic Relations. New York: Oxford University Press.

Epstein, S. and Hornstein, N. 2005: Letter to the editor (re: D. Graddol, 2004: The future of language. Science, 303, 1329-21). Language, 81.1, 3-6.

Epstein, S. and Seely, T. 2002: Introduction. In S. Epstein and T. Seely (eds), Derivation and Explanation in the Minimalist Program. Oxford: Blackwell.

Epstein, S. and Seely, T. 2006: Derivations in Minimalism. Cambridge: Cambridge University Press.

Fitch, W., Hauser, M. and Chomsky, N. 2005: The evolution of the language faculty: clarifications and implications. Cognition, 97.2, 179-210.

Fodor, J. 1974: Special sciences, or the disunity of science as a working hypothesis. Synthese, 28, 97-115.

Gallistel, C. 1997: Neurons and memory. In M. Gazzaniga (ed.), Conversations in the Cognitive Neurosciences. Cambridge, MA: MIT Press.

Gallistel, C. 2005: Learning organs. Manuscript, Rutgers University. To appear in J. Bricmont and J. Franck (eds), Cahier: Noam Chomsky, as L'apprentissage de matières distinctes exige des organes distincts. Paris: L'Herne.

Gallistel, C. 2006: The nature of learning and the functional architecture of the brain. In Q. Jing et al. (eds.), Psychological Science around the World, Volume 1. Proceedings of the 28th International Congress of Psychology. Sussex: Psychology Press.

Gould, S. 1985: Not necessarily a wing. Natural History 94, 12-25. Reprinted in Gould, S. 1991: Bully for Brontosaurus. New York: W.W. Norton \& Company.

Grene, M. and Depew, D. 2004: Philosophy of Biology. Cambridge: Cambridge University Press.

Harvey, W. 1628: Exercitatio anatomica de motis cordis et sanguinis in animalibus. R. Willis, (trans.) A. Bowie (rev.), Harvard Classics (ed.) Frankfurt am Maine. 
Hempel, C. 1959: The logic of functional analysis. In C. Hempel (ed.), 1965: Aspects of Scientific Explanation. New York: Free Press.

Hoffman, D. 1998: Visual Intelligence. New York: Norton.

Jenkins, L. 2000: Biolinguistics: Exploring the Biology of Language. Cambridge: Cambridge University Press.

Kayne, R. 1994: The Antisymmetry of Syntax. Cambridge, MA: MIT Press.

Krafft, F. 1982: Die idée der Zweckmäßigkeit in der Geschichte der Wissenschaften. Berichte zur Wissenschaftsgeschichte 5, 1-152.

Lange, M. 2004: The autonomy of functional biology: a reply to Rosenberg. Biology and Philosophy, 19, 93-109.

Mayr, E. 2004: What Makes Biology Unique? Considerations on the Autonomy of a Scientific Discipline. Cambridge: Cambridge University Press.

Nagel, E. 1961: The Structure of Science: Problems in the Logic of Scientific Explanation. New York: Harcourt Brace and World, Inc.

Newell, A. 1990: Unified Theories of Cognition. Cambridge, MA: MIT Press.

Poeppel, M. and Embick, D. 2004: Defining the relation between linguistics and neuroscience. In A. Cutler (ed.), In press: Twenty-first Century Psycholinguistics: Four Cornerstones. Mahwah, NJ: Laurence Erlbaum Associates.

Putnam, H. 1975: Philosophy and our mental life. In Mind, Language and Reality: Philosophical Papers Vol. 2. London: Cambridge University Press.

Rosenberg, A. 2001: Reductionism in a historical science. Philosophy of Science, 68, $135-168$.

Salmon, W. 1989: Four Decades of Scientific Explanation. Minneapolis: University of Minnesota Press.

Smith, N. 2002: Frogs, parrots, grooming, the basal ganglia and language. Glot International, 6.6, 168-170.

Whitehead, A. 1938: Modes of Thought. New York: The Free Press (A division of MacMillan Publishing Co. Inc.). 